\title{
AUTORIDAD Y ESCUELA. UN ANÁLISIS HISTÓRICO DESDE LAS EXPERIENCIAS DEL INSTITUTO NACIONAL. 1973-2010
}

\author{
Paula Subiabre Vergara ${ }^{1}$
}

\section{Resumen / Abstract}

El presente artículo busca analizar las transformaciones que ha sufrido la autoridad del profesor en la escuela chilena a través de un estudio de caso. Para ello se analizará la noción de autoridad desde una perspectiva histórica en la cultura escolar del Instituto Nacional a través de 4 periodos: 19731977, 1982-1986, 1990-1994, 2006-2010. A partir de entrevistas realizadas a ex alumnos del Instituto Nacional se observarán las maneras en que se ha concebido la autoridad en las distintas épocas y las transformaciones que se han producido en los periodos señalados. Durante las últimas décadas se han producido cambios sociales caracterizados por una nueva manera de entender la autoridad, caracterizada por el dialogo, el consenso, la comprensión etc. Esto ha favorecido la democratización de las relaciones sociales y por tanto ha influido en las formas en que se ejerce la autoridad.

Palabras clave: autoridad, cultura escolar-transformaciones-Instituto Nacional.

\section{AUTHORITY AND SCHOOL. A HISTORICAL ANALYSIS FROM THE EXPERIENCES OF THE NATIONAL INSTITUTE. 1973-2010}

This article seeks to analyze the transformations that has experienced the teacher's authority in chilean schools through a case study. In order to do this, the notion of authority will be analyzed from a historic perspective in the school culture of the Instituto Nacional through four periods: 1973-1977, 19821986, 1990-1994, 2006-2010. Starting from interviews performed to Instituto Nacional's former students, ways in which authority has been conceived in different times will be observed, and the transformations that have been produced

$1 \quad$ Universidad de Santiago de Chile. E-mail: paulasubiabre.v@gmail.com 
during the indicated periods. Over the past decades there have been social changes characterized by a new understanding of the authority, characterized by dialogue, consensus, understanding etc. This has encouraged the democratization of social relations and, therefore, has influenced the ways in which authority is exercised.

\author{
Keywords: authority, school culture, transformations, Instituto \\ Nacional.
}

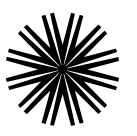

\title{
Introducción
}

A partir del año 2011 se ha presenciado la irrupción de los estudiantes que se han manifestado para incidir y participar de los debates acerca de la educación pública. Estos rechazan el actual modelo educacional y sostienen la necesidad de una reforma estructural al sistema chileno que tenga como base el fortalecimiento del rol del estado en la educación y la eliminación del lucro. La participación activa de los estudiantes a través de las manifestaciones callejeras, tomas y actos de violencia pareciera no tener vuelta atrás, lo que claramente ha incidido en la interrupción del normal funcionamiento de las clases. Además de la masividad de las manifestaciones y el apoyo que ha tenido el movimiento a nivel nacional, ha llamado la atención el empoderamiento de los estudiantes como actores sociales relevantes, lo que se refleja en su disposición a fortalecer las identidades juveniles, y la necesidad de distinguir el movimiento estudiantil de las propuestas educativas del mundo adulto.

La relevancia de este conflicto, por un lado pone en evidencia la necesidad que la historia se haga cargo de estudiar la escuela como espacio de expresión de nuestra sociedad y por otra parte, releva la importancia de reflexionar acerca de la noción de autoridad presente en relaciones cotidianas entre profesores y estudiantes. Pese a la importancia del problema en cuestión, las investigaciones sobre la escuela se han enfocado principalmente en materias como las políticas públicas de los distintos gobiernos, el curriculum, la relación entre la escuela y el proyecto nacional, etc. (Núñez, 1986; PIIE, 1984; Cox, 2005) Si bien existen investigaciones históricas que se centran en la realidad cotidiana de las escuelas, se han dedicado a estudiar la escuela decimonónica, (Egaña, 2000; Toro, 2008) por lo que la presente investigación busca ser un 
aporte al investigar relaciones cotidianas en el espacio escolar en la historia reciente.

Este artículo se inserta en la problemática a través de la noción de autoridad, debido que, tanto en las reflexiones más habituales del actual conflicto estudiantil, como en el "sentido común", se sostiene que la autoridad del profesor sufre una profunda crisis: en las escuelas actuales el profesor tiene grandes dificultades para ejercer su autoridad. La noción de crisis de la autoridad pedagógica supone según Paola Gallo, que “existe un 'antes' y un 'después' en nuestras escuelas (antes las escuelas eran ordenadas homogéneas, escasamente conflictivas y ahora, las escuelas son violentas desordenadas y sin autoridad)" (Gallo, 2011: p.17) Esta visión extremadamente simplificada se nos diluye en el momento en que nos adentramos en la cotidianeidad de la escuela del pasado y del presente, donde es posible observar una serie de continuidades y cambios que se presentan en la figura del profesor como autoridad en la sala de clases. Por esta razón un análisis histórico de nuestra escuela (por lo tanto de su evolución en el tiempo) permite una reflexión mucho más rica si queremos adentrarnos al problema de la autoridad.

Entendiendo que la autoridad no es una condición innata del profesor dada por la escuela, sino que es una construcción social cotidiana entre el profesor y los estudiantes, (en el sentido de que el profesor representa una figura de autoridad en la medida que los estudiantes obedecen) dicha relación se analizará a través de un estudio empírico, el caso de un establecimiento que tiene una cultura escolar particular. Para este análisis se escogió el Instituto Nacional. La elección del Instituto Nacional como objeto de estudio no es azarosa. Desde los inicios de la vida republicana, el Instituto Nacional, fundado en 1813, se ha transformado en el 'ideal' de la enseñanza pública; en sus inicios como principal centro educativo secundario del país y centro de discusión en educación, y hoy uno de los liceos emblemáticos más importantes.

Tratar el problema de la autoridad desde una perspectiva histórica apunta a analizar las transformaciones que se evidencian en la figura de la autoridad en la escuela. Para ello, se han escogido 4 momentos, en los que se produjeron importantes cambios tanto político- sociales como educacionales. El primer momento de estudio, de 1973 a 1977, se inició con el Golpe de Estado, a partir del cual, se aplicó una política de intervención y control de los establecimientos educacionales y de la actividad de los docentes. El segundo momento de estudio, 1982 a 1986, permite apreciar las reformas que instalaron la política de mercado en la escuela, como la municipalización y la 
privatización que afectaron tanto al sistema educacional en general como a docentes y estudiantes; además esta etapa está marcada por las movilizaciones secundarias en contra del régimen militar, siendo el año ' 86 un año clave en el ciclo de protestas. Un tercer momento, que va de 1990 a 1994, corresponde al proceso de transición a la democracia y las primeras reformas educacionales del gobierno de la Concertación de Partidos por la Democracia. Por último, el periodo de 2006 a 2010, se caracteriza por una mayor consolidación de las reformas educacionales de los gobiernos de la Concertación, y por ser un período marcado por el posicionamiento de los estudiantes como actores relevantes, especialmente durante la "revolución pingüina".

La investigación apunta a determinar cuáles son las transformaciones que se evidencian en la autoridad en las relaciones entre profesor y estudiante en el Instituto Nacional que se puede apreciar entre los periodos: 1973-1977, 1982-1986, 1990-1994, 2006-2010, teniendo en cuenta los cambios que se han producido en el sistema educativo chileno en dichos años

La hipótesis que sustenta esta investigación es que durante las últimas décadas se han producido cambios sociales que han apuntado a una mayor horizontalidad en las relaciones sociales. Esto ha conducido a una relación entre adultos y jóvenes, caracterizada por el dialogo, el consenso, la comprensión etc. Esto ha favorecido la democratización de las relaciones sociales en la escuela y por tanto, ha influido en las formas en que se ejerce la autoridad. Junto con esto, los cambios que se han producido en el sistema escolar y en el país, han tendido a reforzar la existencia de una autoridad democrática en la escuela.

\section{El concepto de autoridad}

En su estudio sobre los tipos de dominación, Weber, diferencia el concepto de Herrschaft (dominación), de Macht (poder). En esta distinción se encuentra lo esencial que existe en una relación de autoridad. Weber denomina Herrschaft a la "probabilidad de que, en un grupo determinado de personas, determinadas órdenes o todas las órdenes, encuentren obediencia. No es por tanto la probabilidad de ejercer un poder (Macht) o una influencia sobre los demás". (Weber, 2007: p.63) Desde la perspectiva de Weber, en toda relación de autoridad existe una obediencia voluntaria, que permite asegurar el cumplimiento del mandato de una persona a otra. La obediencia significa "que la acción de quien obedece se desarrolla básicamente como si esa persona 
hubiera convertido en máxima de su comportamiento el contenido de la orden por sí mismo, es decir, solamente por la relación formal de obediencia sin tomar en consideración su propia opinión sobre el valor o ausencia de valor de la orden como tal". (Weber, 2007: p.63)

En la noción de autoridad de Weber, la relación mando-obediencia, es la aceptación de ese mandato recibido como legítimo. "Ninguna dominación se conforma voluntariamente con motivos solamente materiales o solamente afectivos para que sea probable su permanencia. Toda dominación procura más bien, despertar y cuidar la fe en su legitimidad". (Weber, 2007: p.61) Para Weber lo realmente importante en esta relación es que la aceptación del mandato se produce por considerar legítimo al poder del que emana, por lo cual su pregunta fundamental apunta al tipo de legitimación que se le puede atribuir a la dominación, desde donde formula su clasificación de los tipos de dominación (tradicional, racional-legal y carismática). Desde esta perspectiva, según sea el tipo de legitimidad de la autoridad, será el tipo de dominación y el tipo de obediencia que se produzca en la relación de autoridad.

Para efectos de esta investigación, se utilizará una noción relacional de la autoridad, en el sentido de que ésta sólo existirá cuando hay alguien que mande y otro que obedezca. Particularmente se utilizará la noción de autoridad pedagógica, debido a que esa relación mando-obediencia se produce en el escenario particular de la escuela, donde existe una jerarquía en la que el profesor ocupa el lugar del que manda y el alumno del que obedece. Pese a ser una relación jerárquica, la autoridad siempre es legítima, puesto que quien obedece, lo hace de manera voluntaria, eliminando la violencia o fuerza de todo ejercicio de autoridad.

\section{La cultura escolar del Instituto Nacional}

Los inicios heroicos del establecimiento están permanentemente presentes en lo que implica "ser institutano". En las fuentes revisadas, una y otra vez se vuelve a este momento fundante, en el que los próceres deciden organizar el Instituto Nacional como uno de los símbolos del nacimiento de la nueva patria.

$\mathrm{Al}$ iniciarse la Independencia surgió la idea de crear una institución de educación superior acorde a las ideas ilustradas de la época. En la propuesta 
de Henríquez se plasmarán las palabras que todavía dan cuenta del principal objetivo el Instituto Nacional: "el gran fin del Instituto es dar a la patria ciudadanos que la defiendan, la dirijan, la hagan florecer y le den honor" (Boero, 1963: p.11)

A lo largo del siglo XIX el Instituto Nacional se consolidó como el principal establecimiento secundario del país y centro de discusión sobre educación. Además de la importancia mítica de su fundación ligada a la independencia de Chile, forman parte de su memoria histórica los grandes hombres de la historia de Chile que pasaron por sus aulas. Se destacaron políticos, científicos, literatos, artistas, profesionales y por supuesto los 16 presidentes de Chile que se cuentan entre sus ex alumnos o ex profesores.

\section{¿Quiénes son los alumnos del Instituto Nacional?}

Uno de los aspectos que rescatan tanto los ex alumnos como los ex profesores, es que el Instituto Nacional (como símbolo de la educación pública) ha favorecido siempre la meritocracia, ya que ingresan alumnos de todas las clases sociales y de diferentes comunas de Santiago. De acuerdo a los relatos, este es uno de los elementos que hace especial al Instituto Nacional, pues es posible encontrar una especie de microsociedad, donde alumnos de diferentes grupos sociales, religiones, tendencias políticas conviven en un mismo espacio escolar.

Para corroborar esta información se buscaron datos que dieran cuenta de la condición socioeconómica de los alumnos que se matriculan en el IN, y si esa composición social variaba en el tiempo. Según los datos obtenidos en la encuesta IVE-SINAE, los índices de vulnerabilidad que presenta el Instituto Nacional en los últimos años son: 2008 Básica 50,1\%, Media 51,9\%; 2010 Básica 41,6\%, Media 37,5\%; 2011 Básica 39,8\%, Media 36,9\%. Los índices de vulnerabilidad en los últimos años son bastante altos lo que evidencia que muchas familias ven en el Instituto Nacional una de las únicas posibilidades de entregar una buena educación a sus hijos (y por lo tanto de ascenso social).

Estos datos entregan solamente información sobre la última década, pero no dicen nada acerca de si esta composición social ha tenido transformaciones en el tiempo. En los libros de clases se encontró la comuna de residencia de los alumnos, lo que ayudó a tener una aproximación sobre qué alumnos asistieron 
al Instituto Nacional. Para esto se revisó un total de 278 alumnos para el primer periodo, 403 para un segundo periodo, 427 para el tercer periodo y 468 para el cuarto periodo. Si bien es un porcentaje bastante menor en relación a la cantidad de alumnos permite una primera aproximación para conocer su procedencia.

\section{Mapa 1:}

comunas de residencia alumnos 1973-1977

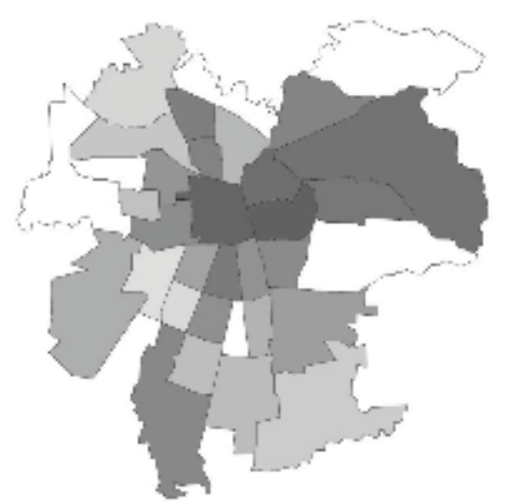

Fuente: elaboración propia a partir de los libros de clases del Instituto Nacional.
Mapa 2:

comunas de residencia alumnos 1982-1986

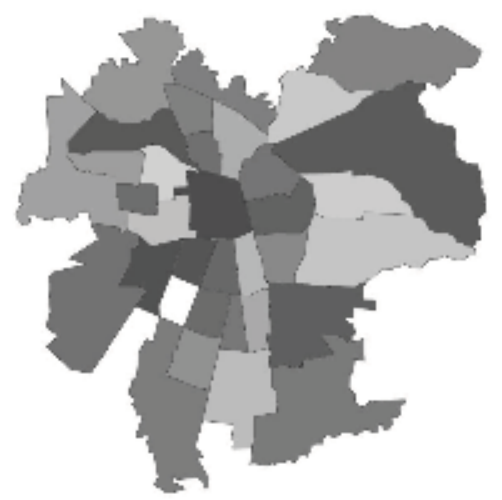

Fuente: elaboración propia a partir de los libros de clases del Instituto Nacional. 
Mapa 3:

comunas de residencia alumnos 1990-1994

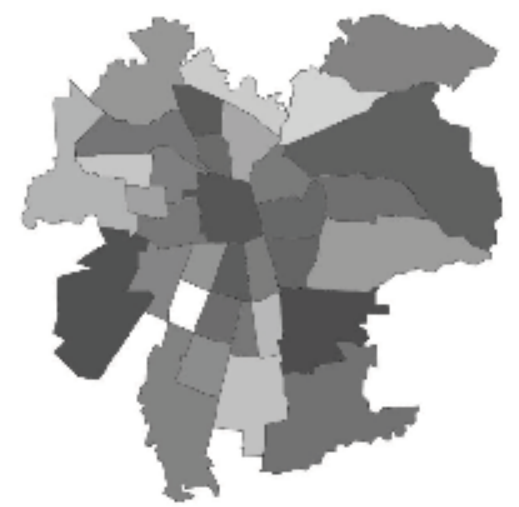

Fuente: elaboración propia a partir de datos obtenidos en los libros del Instituto Nacional.
Mapa 4:

comunas de residencia alumnos 2006-2010

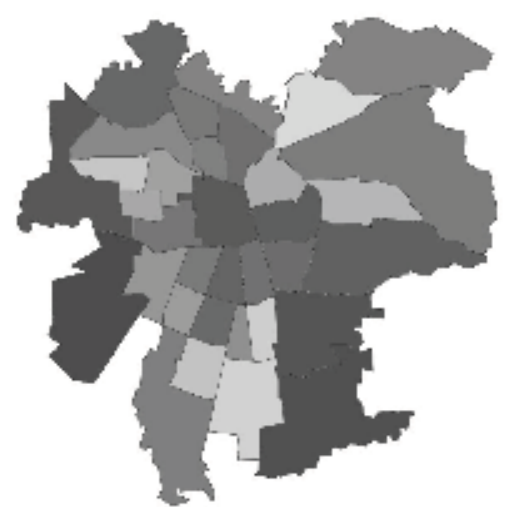

Fuente: elaboración propia a partir de los libros del Instituto Nacional.

Cómo se puede observar en el Mapa 1 (en donde los colores más oscuros indican mayor cantidad de alumnos y los más claros menor cantidad de alumnos), durante el periodo 1973-1977 los alumnos provenían de todas las comunas de Santiago. Su composición era bastante heterogénea puesto que los alumnos venían tanto de comunas centrales como periféricas de Santiago. Las comunas más representativas de este periodo son las comunas céntricas de Santiago Centro, Providencia y San Miguel y del sector Oriente de Santiago como Nuñoa, La Reina y Las Condes.

El Mapa 2 del periodo 1982-1986, muestra una presencia de alumnos del Instituto Nacional en mayor cantidad de comunas de Santiago. Entre las comunas que tienen mayor presencia de alumnos se encuentran al igual que en el periodo anterior las comunas céntricas como Santiago Centro y San Miguel, y las del sector Oriente Nuñoa y las Condes, pero se agregan comunas periféricas como Maipú y la Florida.

Durante el tercer periodo (1990-1994), como se muestra en el mapa 3, si bien las comunas de Santiago, San Miguel y las Condes continúan teniendo una presencia importante de alumnos, las comunas que mayor cantidad de alumnos 
tienen son La Florida y Maipú. Las comunas centrales son reemplazadas por las comunas periféricas en cuanto a mayor presencia de alumnos.

Porúltimo el periodo 2006-2010, muestra claramente un desplazamiento hacia las comunas periféricas como Maipú, Puente alto, la Florida, Pudahuel, teniendo en cuenta que a pesar de esto, existe presencia de alumnos en todas las comunas de Santiago. Ver Mapa 4.

A partir del análisis de los mapas, se puede sostener que el alumno que ingresa al Instituto Nacional posee una composición bastante heterogénea ya que provienen de las distintas comunas de Santiago. Pese a esto es interesante observar que desde el primer periodo 1973-1977 al último 2006-2010 se produce un desplazamiento de las comunas céntricas y del sector Oriente, hacia comunas periféricas de la ciudad de Santiago, especialmente de las comunas de Maipú, La Florida, Puente alto y Pudahuel. Esto en alguna medida permite señalar una mayor presencia de familias de clase media y media baja en el último periodo, disminuyendo la presencia de alumnos de clase alta.

Cabe señalar que las transformaciones en la distribución del espacio, están en relación con los cambios que ha vivido la ciudad de Santiago. Algunos datos del INE dan cuenta de que las comunas más pobladas son: en $1990 \mathrm{La}$ Florida (325.303 hbts), Maipú (253.966 hbts) y Puente alto (252.360 hbts); y el año 2005 Maipú (627.235 hbts), Puente alto (605.803 hbts) y La Florida (394.821 hbts), (Seremi de planificación y coordinación, 2002) por lo que a partir de la década de los '90, La Florida, Puente alto y Maipú, son las comunas más pobladas, que precisamente corresponden a las comunas de la clase media emergente. Posiblemente lo que muestran estos datos es que las familias de esta clase media emergente ven precisamente en el Instituto Nacional la posibilidad de continuar su ascenso social.

Por otra parte, los cambios en la composición social de los alumnos, dan cuenta que la clase alta y media ha dejado de ver al liceo como lugar de instrucción desplazándose casi exclusivamente a los colegios particulares pagados (recordar que a mediados del siglo XX el liceo chileno todavía era un lugar de educación de élites, y aún más el Instituto Nacional). En este contexto, los establecimientos de educación pública se han vuelto cada vez más homogéneos socialmente, convirtiéndose en lugares casi exclusivos de las clases bajas, generando con ello la casi nula relación entre grupos de distintas clases sociales, perdiendo el capital social (redes) de los mismos. Precisamente, es la escuela secundaria la que genera tanto la posibilidad de la certificación 
educativa, como la construcción de redes, ambos procesos necesarios para el ascenso social.

¿Por qué las familias escogen al Instituto Nacional como lugar de ascenso social? En las entrevistas realizadas (de alumnos y profesores) es bastante recurrente que señalen al IN como un establecimiento excepcional en términos académicos, lo que se explica la mayoría de los casos por la calidad tanto de los profesores, como de los alumnos. Con respecto a los alumnos, estos al ingresar a $7^{\circ}$ básico deben rendir una prueba de selección, además de presentar documentos de acreditación de la enseñanza básica (notas). Debido a la alta demanda de matrículas que tiene el colegio, quienes ingresan al IN corresponden a los alumnos de mejores promedios en sus colegios de origen. A modo de ejemplo, en el 2000, 2001 y 2002, respectivamente, fueron dos mil 800 , tres mil 200 y tres mil 800 los postulantes que buscaban ingresar a 16 séptimos básicos con un total de 700 cupos. (Miranda, 2003).

El hecho de que los alumnos que ingresan al colegio tienen un buen rendimiento influye en el interés que estos tienen por el estudio. Según todas las entrevistas realizadas el tema académico es fundamental, lo que redunda en que exista gran competencia entre los alumnos por obtener buenas calificaciones. Para muchos el gran objetivo de su paso por el colegio es ingresar a la universidad. En las entrevistas realizadas a ex alumnos es común escuchar frases como: "en definitiva lo que pasaba es que no me interesaba en realidad yo estaba ahí para estudiar y el objetivo era la universidad, no otro" (Alumno CG), o "Nosotros fuimos el mejor cuarto del ' 87 todos entraron a la $U$, porque yo tenía amigos que eran de otro cuarto y no le fue tan bien a ese cuarto, o sea de todos los cuartos entraron a la $U$, pero de mi curso entraron todos”. (Alumno AB).

Los altos resultados académicos de los alumnos del Instituto pueden ser comprobados con algunos datos. De acuerdo al ranking publicado por la revista Qué Pasa donde se promediaron los resultados de la PSU entre el 2003 y el 2011, el Instituto Nacional se posiciona en el lugar 11 con un total de 684 alumnos por año promedio que rinden la prueba y con un puntaje de 673,21 promedio, situándose en el primer lugar entre los colegios municipales. (Sala de Historia, 2012) En los últimos 10 años el Instituto Nacional, lidera el ranking de los colegios municipales, además de obtener los primeros lugares a nivel nacional, esto teniendo en cuenta la gran cantidad de alumnos que egresan cada año. Llama la atención también la gran cantidad de puntajes nacionales 
que logra el Instituto Nacional, que en los últimos años ha liderado los rankings siendo el año 2011 un record histórico de 54 puntajes nacionales. ${ }^{2}$

De acuerdo a Bernstein, el orden expresivo, controla la transmisión de las creencias y el sistema moral de una escuela. Además puede considerarse como una fuente de valores compartidos por todos los miembros de la escuela, por lo que tiene una función cohesiva. (Bernstein, 1988) Desde esta perspectiva, resulta fundamental determinar 'los valores y principios' compartidos por los miembros del IN de modo de poder describir su cultura escolar.

Uno de los elementos que es bastante recurrente en los discursos oficiales del IN es el legado de Camilo Henríquez y las palabras que pronunció en su proyecto: "el fin del instituto es dar a la patria ciudadanos que la defiendan, la dirijan, la hagan florecer y le den honor", más allá de lo que significaron estas palabras cuando fueron pronunciadas, esta frase tiene una importancia crucial en el ser institutano, ya que da cuenta del origen republicano del colegio, y de alguna manera el 'deber ser' de la herencia dada por Henríquez. Quienes pasan por las aulas del IN deben ser ciudadanos activos, partícipes de la vida nacional, renombrados, célebres, etc. De alguna manera el IN debe ser la cuna de los grandes líderes del país. Esto fue efectivo en los primeros años de la república, puesto que justamente la elite santiaguina se educaba ahí. A lo largo del siglo XX y más aún en el XXI, la complejización de la sociedad y también del sistema educacional chileno ha hecho que los líderes provengan de distintas partes del país y obviamente de diferentes colegios. Sin embargo, aún existe la convicción de que quienes entran a estudiar al Instituto deben ser los líderes del mañana.

Las palabras de Henríquez no sólo están presentes en la mayoría de los discursos del IN, sino también son inspiradoras de su proyecto de educación. En este sentido las palabras de Henríquez tienen una permanente readecuación de acuerdo a los principios propios de una época, y también a las diferentes coyunturas nacionales, y particularidades propias del colegio. ¿Cómo es posible que los valores impuestos en 1813 se mantengan en el tiempo, pese a los cambios visibles que ha tenido la sociedad chilena?

La libreta de comunicaciones establece explícitamente lo que significa ser institutano. Para el análisis se contó con un ejemplar del año '89, que permite

2 "Puntaje Nacional" es aquel estudiante recién egresado de la educación media que saca 850 puntos en la Prueba de Selección Universitaria (PSU) o el mejor puntaje ponderado en lenguaje y matemáticas. 
observar algunos elementos valorados durante la década de los ' 80 . En esta década ser institutano es "poseer la llama del espíritu del 10 de agosto de 1813, (...) en la más bella y noble tarea que nos legaron los padres de la patria. Cual es dirigir, defender, hacer florecer y darle honor a Chile. Con inteligencia, con el esfuerzo y aporte personal cotidiano, con creatividad, capacidad y auténtico patriotismo. Con afán de servicio desinteresado, desprovisto del fanatismo sectario y sí teñido de amor humanitario". (Instituto Nacional, 1989: p.6) La ciudadanía activa pasa a ser el principal objetivo de la educación institutana, pero ésta principalmente implica un desarrollo individual, que permita el mejoramiento del país. Al mismo tiempo es una ciudadanía apolítica, acorde al tipo de liderazgo que se buscaba en la época de la dictadura militar.

El proyecto educativo institucional, confeccionado en la década de los ' 90 señala que la finalidad educativa del Instituto es formar buenos ciudadanos, entendiendo las palabras de Camilo Henríquez, de manera diferente. Según este documento "Acogiendo el mandato bien inspirado de Camilo Henríquez, se esfuerza por ser un semillero de civismo y cultura democrática, una forja de patriotismo, sobriedad, responsabilidad y generosidad, que se asienta en la capacidad perfectible del hombre". (Instituto Nacional, 2011: p.4) En este sentido se le da al colegio una identidad eminentemente patriótica, no en el sentido nacionalista, sino de fuerte identidad, pertenencia y participación en esta. El IN apunta a desarrollar en su interior un sentido patriótico, de cultura democrática, donde sus estudiantes sean partícipes activamente de esta.

El pasado es revisitado una y otra vez en la cultura institutana, este se representa de una manera 'memorable', 'inmortal'. La fundación del Instituto Nacional, el carácter revolucionario de su creación en pleno proceso independentista, y la trascendencia de quienes pasaron por sus aulas, le ha dado la impronta, la grandeza que tiene hasta hoy. Esa es la representación que tiene el pasado en el ser institutano. Esa representación del pasado a lo largo de los años se reactiva en cada discurso, acto, ritual, y muchas veces en las mismas aulas para transmitir en cada generación ese 'carácter de grandeza' que tiene el Instituto Nacional. Sin embargo, el Instituto 'vive de las glorias pasadas', vive en una suerte de anquilosamiento que le impide observar la realidad actual, los cambios que ha vivido la sociedad, y los cambios que ha sufrido el propio colegio. El uso del pasado refuerza la grandeza del Instituto en vez de observar la realidad del presente y construir para el futuro.

Los documentos analizados dan cuenta de aquellos valores que buscan ser transmitidos principalmente a través de actos oficiales, discursos, documentos, 
etc. Representan en este sentido, el 'ideal' que busca implementar la institución, es decir que el conjunto de principios, valores e inclusive normas que se intentan transmitir corresponden a un determinado proyecto de sociedad que se busca desarrollar. Sin embargo, ¿qué tan efectivos son estos discursos en aquellos que son partícipes del día a día del Instituto Nacional? ¿Cuán representativos son estos ideales de lo que piensa aquellos que estudiaron en el colegio?

A pesar de las diferentes posturas sobre lo que significa ser institutano y sentirse partícipes de esta institución, a través de las entrevistas se pudo percibir una especie de 'mística' que es compartida por la mayoría de los que ha pasado por sus aulas. A pesar de las diferentes posturas existentes, la mayoría de los institutanos posee un gran sentido de pertenencia. Desde la lógica de la crítica, de la valoración e incluso del pragmatismo, existe una fuerte identidad de ser institutano, lo que se traduce en que la mayoría de los ex alumnos continúan juntándose, y reconociéndose como parte de una comunidad.

La mística institutana es algo indescifrable, que no se puede expresar en palabras, pero que está presente, se palpa, es lo que le da ese fuerte sentido de pertenencia que no todas las escuelas poseen. Como se puede apreciar en el siguiente relato, "es que nadie inculcaba los valores, así como 'estos son los valores que tenemos que tener', si no que los valores eran como, algo en el aire que... que todos los que han pasado por ahí se sienten parte del colegio, hay un orgullo de haber pasado por ahí que, que no se tiene o yo no he visto en otros colegios. Hay muchos presidentes que han sido del Instituto Nacional, y si bien eso es así, no es algo que se esté remarcando todos los días de que 'oye, de aquí han salido presidentes', etc. No es algo que se hiciera hincapié a cada rato, de hecho no recuerdo que lo hayan hecho, pero como estaba ahí, uno respiraba un aire que hacía que, todos los que han pasado por ahí, como te digo, tienen un orgullo de haber pasado por ahí." (Alumno CG).

La visión de excepcionalidad que está presente tanto en el discurso escrito (documentos revisados) como oral (entrevistas) está muy relacionado con el uso que se hace del pasado en el Instituto Nacional. Esta identidad de grandeza, 
de trascendencia para el país, transmite de generación en generación la idea de que el colegio es único, y quienes pasan por sus aulas son excepcionales. Nacional

Representaciones de la autoridad de los ex alumnos del Instituto

El siguiente apartado tiene como objeto analizar las representaciones de la autoridad de los alumnos que estudiaron en el Instituto Nacional en diferentes momentos históricos de la historia reciente. Para esto se realizaron 12 entrevista correspondientes a las 4 épocas. Los entrevistados tienen una visión bastante positiva de lo que fue su experiencia escolar, lo que es determinante a la hora de evocar sus recuerdos. Por otra parte, y en directa relación con esta visión positiva, los entrevistados son profesionales exitosos (exceptuando los del último periodo que actualmente se encuentran estudiando en la universidad) y manifiestan que ese éxito se explica en gran medida por su paso por el IN.

Se analizarán los 4 periodos a través de 3 dimensiones que permitirán rescatar tanto las representaciones de la autoridad que existe en cada periodo, como apreciar sus transformaciones en el tiempo. En primer lugar se analiza la dimensión formal de la relación de autoridad, es decir, la 'disciplina escolar', entendiendo esta como el conjunto de normas que rigen una escuela que incluye el modelo de comportamiento que tiene que tener el alumno, la norma propiamente tal y también las rutinas y rituales escolares. Una segunda dimensión corresponde a la participación estudiantil, y su relación con la autoridad escolar. Y una tercera dimensión, donde se analizan las concepciones acerca de la autoridad en cuanto al nivel de cercanía o distancia que se puede apreciar en las experiencias de los ex estudiantes y también a las razones de obediencia y desobediencia que se pueden extraer de los discursos.

\section{Los años de control y autoritarismo (1973-1977)}

En este primer periodo, al preguntar a los ex institutanos sobre las reglas y normas de conducta, estos señalan que la disciplina era bastante estricta y los alumnos debían acatar cierta forma de comportamiento para mantenerse en el colegio. Los alumnos poseían un libro de vida o también llamada "ficha conductual", donde se plasmaba toda la trayectoria conductual del alumno (especialmente las anotaciones positivas y negativas) lo que era determinante para la permanencia del alumno. Tener anotaciones negativas desde la 
percepción de los alumnos no era simple, "tu sabías que el tema disciplinario era jodido. Llegar a tener una anotación negativa en el libro de vida, no sé si tú lo viste, era... complicado". (Alumno AE).

Por otra parte, llama la atención que pese a que los relatos señalan esta rigidez del sistema disciplinario, el respeto a la norma era entendido como algo normal propio de la posición que poseía el alumno en el colegio: la obediencia. "Creo que uno más o menos en ese tiempo entendía que ya en el poco andar de los alumnos que teníamos un año, un poco más de un año en el colegio, ya estaba como establecido un cierto funcionamiento, no sé po, pedir permiso o hacer ese tipo de cosas o salir ¿me entiendes? Funcionábamos bien, era normal por decirlo, no era anormal para nosotros." (Alumno AE)

De acuerdo a los relatos de los ex institutanos el comienzo de la clase constaba de algunos pasos que se seguían a diario: profesor?

"P: cuando empezaba la clase, ¿cómo esperaban los alumnos al

HA: la misma rutina, lo esperábamos en el pasillo o algunos en la sala, tratando de ponerse al día con las tareas o estudiando... la última estudiada del minuto, otros chacoteando en los pasillos ¿no cierto? Se acercaba el profesor, entrabamos todos y ordenadamente "buenos días profesor", era una rutina media, enseñada desde chicos... "buenos días profesor" y se paraba el profesor adelante y esperaba en silencio y ahí todos empezábamos "oye ya cállate, cállate, cállate" era como una rutina habitual de cada inicio de clases, no había una naturalidad en esto, era como un esquema que había que seguir." (Alumno HA).

Cómo se puede apreciar en este pasaje, en el día a día se iba marcando la conducta que debía tener el alumno. El saludo al iniciar la clase era uno de los ritos diferenciadores más importantes donde se iba imprimiendo a través de la rutina la posición que ocupaba el profesor y la posición que ocupaba el alumno. El profesor ocupaba el lugar principal de la sala de clases parado frente a los alumnos sobre una tarima que simbolizaba su autoridad, por otra parte, sin decir ninguna palabra los alumnos se quedaban en silencio momento en el que recién el profesor saludaba, y les permitía tomar asiento. Lo mismo ocurría 
durante la lista; los alumnos debían permanecer en silencio y al escuchar su nombre ponerse de pie y decir 'presente señor'.

Según una investigación de Lechner el año 1982 en escuelas de clases media y baja, el disciplinamiento de los estudiantes comienza precisamente con el saludo. El saludo es "la puesta en escena de la autoridad. Junto con establecer la distancia jerárquica nivela a los subordinados. A la convocatoria de poder responde un alumnado homogeneizado: a una sola voz". (Lechner, 1982)

Durante el desarrollo de la clase, era el profesor el que iba marcando las pautas de la clase. Si el alumno deseaba hablar, expresar una opinión, ponerse de pie o ir al baño, debía levantar la mano y esperar que el profesor le diese permiso, eso era bastante común dentro de la sala de clases. Para los ex alumnos: "uno tomaba como muy normal pedir permiso para pararse, pedir permiso para hacer algo, tenías que pedir permiso, no era como normal que tú te pararas o hicieras cosas... era como muy muy normal, reitero, pedir permiso para algunas cosas" (Alumno AE)

Los momentos de indisciplina tales como conversar, gritar, hacer desorden, tirar el borrador, eran sancionadas por los profesores. Las medidas disciplinarias que se tomaban eran el reto, anotación negativa, expulsión de la sala de clases, enviar a inspectoría, citación al apoderado, suspensión de clases, condicionalidad y expulsión del colegio, dependiendo de la gravedad de la falta.

La disciplina no sólo era importante en la sala de clases, sino que el alumno debía tener un comportamiento adecuado dentro del colegio. En los ritos como los actos cívicos, aniversario del colegio, inicio de clases etc. se marcaban los espacios que ocupaban los distintos actores del colegio. Los alumnos formados en hileras de a uno, al frente el profesor que les correspondía y en la testera se sentaban las autoridades del colegio: el rector, los inspectores generales, un militar, y atrás el resto de los profesores. Los actos mostraban claramente la posición de los actores dentro de la jerarquía de la escuela, ocupando las autoridades el lugar privilegiado del acto.

El comportamiento del alumno incluía también el aspecto físico de este. Tanto los profesores como los inspectores tenían un riguroso cuidado de la presentación personal de los alumnos que incluía pelo corto, bien afeitados, uniforme completo que incluía: chaqueta azul, corbata e insignia y limpieza. El no cumplimiento de estos requisitos tenía consecuencias importantes para 
el alumno: "tu podías andar con el pelo un poco más [largo], pero no pelo largo, definitivamente no, definitivamente no podías andar con algo que fuera absolutamente opuesto al uniforme. $\mathrm{O}$ sea tu puedes, de repente, no sé po, ya creo que en $4^{\circ}$ nos exigieron bastante menos pero tu tenías que estar al menos con esa chaqueta azul que se usaba, no podías entrar con otra cosa, no te dejaban entrar, simplemente. Y eso se vigilaba en la entrada, en la entrada, así de simple." (Alumno AE).

Laparticipación estudiantilactiva fue uno delos elementos característicos de los establecimientos educativos emblemáticos antes de la dictadura militar. En el caso del Instituto Nacional, el CAIN tenía una participación bastante potente, además de estar fuertemente politizado y permeado por las colectividades políticas que existían a nivel nacional. Una de las principales medidas que tomó el régimen militar en las escuelas fue el sometimiento a través del Ministerio de Educación de todos los establecimientos educacionales, prohibiendo en su interior cualquier tipo de participación política. En este contexto, en las escuelas se eliminaron todas las organizaciones de profesores, alumnos y apoderados, y posteriormente se formaron organizaciones designadas por las autoridades de cada establecimiento.

La circular aclaratoria n 22 del 18 de Marzo de 1974, precisó la vigencia del receso indefinido de las federaciones estudiantiles, que se mantenía desde el 11 de septiembre de 1973, mientras que en agosto del mismo año el ministerio emitió otra circular en la que se establecían las bases para la organización de los centros de estudiantes. En dicha circular se establecía que el "centro de alumnos es la organización educativa que en cada establecimiento, forman los estudiantes de educación media", en donde su organismo más importante "será la asamblea de delegados de cursos que estará compuesta por los delegados de todos los cursos de educación media que existan en el establecimiento y que serán nombrados por los alumnos de cada uno de dichos cursos". En la circular se establece explícitamente que los centros de alumnos "no podrán intervenir en actividades políticas, religiosas en materias pedagógicas ni tampoco en la administración y organización escolar del establecimiento", además de presentar un artículo transitorio en el que se señala que mientras se establezcan definitivamente las normas sobre la elección de los Centros de Alumnos, estos "serán designados por las autoridades correspondientes y permanecerán en 
sus funciones con la plenitud de sus atribuciones." (Ministerio de educación, 1974).

En el caso del Instituto Nacional no fue posible identificar los años en que funcionaron los Centros de Alumnos designados, pero si se puede señalar que no tuvieron un rol activo durante esos años. Los ex alumnos, responden que 'no recuerdan bien si había' o 'parece que había, pero no recuerdo que hacían', etc. Lo que sí recuerdan los ex alumnos son los 'Consejos de Curso'. El Consejo de Curso de acuerdo a la circular citada "es el organismo base del Centro de Alumnos y estará constituido por los alumnos de cada uno de los cursos de educación media del establecimiento". (Ministerio de educación, 1974) Cada consejo de curso en el Instituto Nacional debía ser dirigido por una directiva compuesta por un presidente, un secretario, un tesorero, un delegado de curso y el jefe de disciplina, los que se elegían de forma democrática en el curso. Dentro de la carga horaria semanal estaba establecida una hora de consejo de curso, que se utilizaba para organizar acciones como juntar plata, realizar actividades de esparcimiento, fiestas, paseos, etc.

Un típico consejo de curso consistía en: “profesor llevándola... profesor jefe llevando la tabla, él la ponía, él ponía los temas que se llevaban a cabo, hacía una... tocaba temas contingentes del proceso educativo, evaluaciones, ramos conflictivos, cosas que tuvieran problemas... había una parte de orientación y había una parte, que nos cedíamos a nosotros la palabra, para actividades varias, siempre organizábamos carretes, ese tipo de cosas." (Alumno HA)

Los niveles de participación de los alumnos eran bastante restringidos, y aquellos espacios que existían eran intervenidos por los adultos. Tal como se puede apreciar, en el consejo de curso los alumnos tenían escasa autonomía para imponer sus debates o intereses, y era el profesor quien señalaba los puntos importantes que debían debatirse.

Si observamos por otra parte, la visión que tienen los ex alumnos de sus profesores, se puede apreciar una visión bastante positiva. Describen a los profesores del Instituto Nacional, con un nivel académico excepcional lo que les permitió tener un nivel de conocimientos superior al de otros colegios. El profesor ideal del instituto era aquel que destinaba el mayor tiempo de la clase a 'pasar materia', tal como lo describe un ex alumno: "era el profesor que pasaba toda la materia, que exigía más, el que llegaba a la hora a clases y salía hasta el último minuto pasando materia. Esa era como la dinámica instructiva del Instituto Nacional; instruía y daba conocimientos, daba 
muchos conocimientos y pasaba toda la materia y... no era formativa, esa era la gran diferencia entre algunos colegio y el Instituto." (Alumno HA) La idea de 'buena enseñanza' que compartían tanto alumnos como profesores, era la de transmitir conocimientos, en donde el alumno era el sujeto pasivo y el profesor basaba su autoridad en la entrega de contenidos y saberes 'objetivos'.

En general este tipo de profesores generaba relaciones bastante distantes con los alumnos. Cuando se les preguntó a los ex alumnos sobre cómo era la relación con los profesores las respuestas fueron: "ese colegio es una máquina de clases, entonces tenían que estar corriendo para todos lados, tiempo no había, muy poco" (Alumno HA) o también "pasaban su materia, llegaban, salían y cuando trataban de intimar un poco más, era casi criticado te diría yo, era como tildado de flojo, porque no pasaba materia" (Alumno CG). El centrar la labor del profesor en la excelencia académica, según la apreciación de los ex alumnos, daba pocas instancias para poder generar una relación de mayor cercanía entre el profesor y sus alumnos.

La distancia y jerarquía en la relación entre profesor y alumno era además reforzada por una forma de hacer clases donde no había mayor preocupación de si el alumno aprendía o no. De acuerdo a los entrevistados, las clases en su mayoría eran bastante expositivas, donde el profesor 'pasaba la materia' y los alumnos debían escribir. En ese contexto "con suerte la mitad aprendía y la otra mitad anotaba y no aprendía. ¿Por qué? No por culpa... bueno, por culpa del profe en parte porque hacía una clase estilo universidad" (Alumno CG).

Según Lechner, el aprendizaje repetitivo como el que se puede apreciar en las entrevistas, refuerza la autoridad del profesor, ya que "lo que probablemente aprende el niño, el mensaje que recibe y graba es que el profesor es el que manda y es dueño de la verdad. Él sabe cuándo algo está bien o cuando está mal sin tener que argumentar las razones" (Lechner, 1982: p.10). En ese sentido, el aprendizaje repetitivo refuerza un tipo de profesor autoritario, donde no existe posibilidad de discusión con el 'saber' que el profesor entrega.

Al analizar las entrevistas de este periodo se puede señalar que las razones de la obediencia están siempre relacionados con dos conceptos: el respeto y el miedo. En primer lugar los entrevistados rescatan que en la época en que ellos estudiaron existía respeto por el profesor en general. Ese respeto iba más allá del profesor que estaba enseñando y además estaba respaldado socialmente. Por ejemplo "en esa época los profesores tenían respaldo de los colegios, en el sentido que podían ser seres estrictos. Ahora un profesor 
estricto, va el apoderado y reclama ¿no cierto? Si le dice que se va por culpa de ella iya? Entonces eso antes no sucedía, antes los padres iban para que al hijo no lo trataran... no lo discriminaran o no... que no hubieran profesores barristas o si tenía mala conducta, a justificarlo. Pero no iban como en contra del profesor o en contra del colegio. Era algo completamente diferente a lo que se da ahora." (Alumno CG).

Aquellos profesores que eran más obedecidos eran precisamente los que causaban miedo. El miedo iba ligado estrictamente al ámbito académico: miedo a obtener malas calificaciones, miedo a repetir de curso y finalmente miedo a ser expulsado del colegio. Por ejemplo: "tenía un profesor de historia creo, donde no se podía hacer nada en clases, una risa, conversación, un bostezo... te llamaba y te hacía una pregunta, si no sabías te ponía un uno en su cuaderno... si después mejorabas te iba borrando los unos". (Alumno CG)

\section{La Municipalización y la movilización estudiantil (1982-1986)}

Las normas explícitas, modelos de comportamiento y rutinas escolares no tienen un cambio sustantivo durante esta etapa. En los relatos de los ex institutanos queda en evidencia la existencia de una disciplina bastante estricta, en donde el alumno debía mantener un cierto comportamiento considerado adecuado por las autoridades del colegio. Al igual que en el periodo anterior, el aceptar estas reglas estaba relacionado con el 'miedo a ser expulsado del colegio' y de perder la oportunidad de educarse en el 'mejor colegio de Chile'.

En la sala de clases debía haber respeto al profesor y en la mayor parte del tiempo silencio. Conversar, reírse o pararse en la sala, ya era motivo de sanción. El silencio, además de ser necesario para el aprendizaje de los alumnos, es un ejercicio de autoridad. Para Lechner, el silencio "exige respeto por la mera presencia del profesor. Recuerda que la palabra es un atributo de la autoridad y que sólo ella distribuye su uso" (Lechner, 1982: p.15). El alumno no tiene derecho hablar mientras el profesor no se lo permita.

$\mathrm{Al}$ igual que en el periodo anterior, el control de la presentación personal era bastante riguroso. En los entrevistados de este periodo es incluso mucho más explícito el cuidado que se pedía en términos de presentación personal, señalando que los alumnos debían estar ordenados, con corbata, camisa, pantalón con la raya planchada, zapatos lustrados, calcetines oscuros, limpieza. 
Inclusive, en algunas ocasiones los alumnos se paraban fuera de la sala y se les revisaba las manos, el pelo, la limpieza, y el correcto uso del uniforme. Quien no cumplía con estas reglas, no podía ingresar a clases.

Algo que es bastante interesante durante este periodo, es que la reaparición de la 'política' en ocasiones tuvo efectos en la disciplina escolar. A partir del año 83 se producen las primeras protestas contra la dictadura, por lo que algunos alumnos comienzan a tener militancia política de oposición al régimen. En muchos casos ese descontento se tradujo en 'rebeldía' al interior del colegio. Tal como aparece en el relato de un ex dirigente del Partido Institutano de Oposición (PIO): "me achacaban problemas conductuales, estuve suspendido y todo, pero por pegar un papelógrafo que decía 'mañana marcha en tal lugar y todo' no era que yo le había faltado el respeto a un profesor, o que yo le había pegado a un compañero, que me haya robado algo o ese tipo de cosas no. Que fuera irrespetuoso con los profesores, no, jamás. Pero si, digamos, estaba en contra del sistema político del colegio, eso es... se puede, o sea, en ese tiempo era mala conducta, hoy en día no." (Alumno AZ)

Si bien la participación política en la mayoría de los casos funcionó de manera clandestina, el relato muestra que el tipo de comportamiento que el alumno debía tener en el colegio estaba marcado por lo político, y aquel que se salía de ciertos límites era expulsado. La diferencia con el periodo anterior es que antes de la reaparición de la política, la rebeldía y oposición no era algo evidente. A mediados de los ' 80 , si bien existe mucho temor, y la rebeldía más explícita no se daba en la totalidad de los alumnos, ésta existió.

En esta etapa hay bastantes cambios en torno a la participación estudiantil tanto en los espacios institucionales como en las organizaciones autónomas de los alumnos. El decreto 736 del año 1985 del Ministerio de educación, fija el reglamento de Centros de Alumnos. A partir de este momento se establecen las funciones y forma en la que se constituirán los Centros de Alumnos, que en el caso del Instituto Nacional funcionará hasta el año 1988, cuando se elige por primera vez un centro de alumnos democrático. El reglamento señalaba que la directiva del centro de alumnos debía conformarse por un presidente, un vicepresidente secretario ejecutivo, un secretario de finanzas y un secretario de actas. De acuerdo al reglamento la directiva, debía ser elegida "anualmente por el consejo de delegados de curso, de entre sus miembros" los que debían tener como requisitos, "b) Haber sido promovido con un promedio de notas que lo ubique en el tercio superior de su curso, haber obtenido un informe educacional favorable c) no haber sido destituido de algún cargo del centro de alumnos 
por infracción a sus reglamentos, d) no tener matrícula condicional". Además establecía claramente que "no podrá intervenir en actividades políticas ni en materias técnico- pedagógicas o en la administración y organización escolar del establecimiento." (MINEDUC, 1985) De esta manera, institucionalmente se restringía la votación sólo aquellos que eran delegados de curso (presidente de curso), y se limitaba la participación a aquellos que cumplían con un determinado perfil (buenas notas y comportamiento adecuado).

De acuerdo a los ex alumnos entrevistados, el Centro de Alumnos cumplía un rol instrumental, ya que se dedicaba a organizar algunas actividades de esparcimiento, con especial énfasis en el aniversario del colegio. Claramente, el Centro de Alumnos no tenía o no mostraba una opción política, ya que estaba estrictamente prohibido, en esto también jugaba un rol fundamental el miedo que existía a expresar opinión política. El siguiente relato es muy clarificador en ese sentido: "La tendencia era obviamente más bien opositora del grueso, no estaban conforme con el tema, pero nunca lo presentaron (...) Por eso te decía yo que el Centro de Alumnos era bastante light para actividades bonitas, estaban parados. Pongamos a nosotros nos llevaban como colegio, cuando existía este tema que me acuerdo, de las armas cuando entraron en Carrizal Bajo, a nosotros nos llevaban como colegio a la Escuela Militar a ver las armas... todo lo que encontraron. (...) Entonces por eso que nadie opinaba, es decir, si teníai un paseo a la Escuela Militar a ver a... tú te subías al bus, ibas y mirabas y te subías al bus y de vuelta, nada más." (Alumno CM)

La otra instancia institucional de participación era el consejo de curso, que era dirigido por una directiva que debía elegirse en todos los cursos. Esta estaba integrada por el presidente, el vicepresidente, el secretario y el tesorero, cargos que eran elegidos por votación democrática. Sin embargo, se exigían ciertos requisitos como: "buen rendimiento (mínimo 5,5 promedio de notas), presentación personal excelente, condiciones de líder positivo, respetuoso del reglamento interno del colegio, dispuesto a integrarse y participar en todas las actividades académicas y paracadémicas programadas por el Instituto." (Instituto Nacional, 1984) Por lo tanto, la directiva de curso también se ajustaba a un cierto tipo de alumno determinado por el colegio. El consejo de curso era utilizado para organizar distintas actividades como fiestas, paseos, partidos de futbol, cumpleaños, etc, y resolver problemas puntuales que tenía el curso con algunas asignaturas y/o profesores.

Los canales institucionales de organización estudiantil daban poco espacio de libertad a los alumnos para discutir sobre temas de mayor 
relevancia, o poner en el debate temas de su interés. En ese contexto y sumado al surgimiento del movimiento secundario como actor relevante en la lucha contra la dictadura, surgieron organizaciones autónomas del estudiantado que tuvieron además gran relevancia nacional. A partir del año ' 81 , se crearon los CODE (Comité democráticos), los que funcionaron como una suerte de orgánica paralela a los centros de alumnos. En estas organizaciones participaban militantes e independientes de los distintos grupos y partidos de izquierda. En el Instituto Nacional, el CODE tenía un nombre propio, el Partido Institutano de Oposición.

Según los entrevistados si bien no había discusión política permitida, la politización dentro del colegio se apreciaba de diferentes formas. Según el relato de un ex alumno no comprometido políticamente, los estudiantes sabían "que ellos pertenecían... que ellos eran participantes activos de lo que es protesta y todo el tema, pero obviamente nadie... nadie opinaba (...) Pero sí se daba mucho en el colegio que estaba la... los rayados, de repente había unos rayados del PIO, del FIN, pero tu sabías que estaban los dos... estaban esas dos tendencias, estaban dentro del colegio." (Alumno CM)

El tipo de protesta que se realizaba en el colegio era totalmente clandestina y consistía en acciones que se realizaban durante los recreos como "sabotear los baños, pegar papelografos, tirar bombas de humo y dirigirse como dirigente como un encapuchado ¿no cierto? ‘ Compañeros tenemos que hacer esto, tenemos que juntarnos con los demás, porque esto es el colmo, la municipalización, el sistema político, los muertos, esto, esto otro, aquí, allá!' recreo y después volvíamos a clases; al otro recreo lo mismo." (Alumno AZ) El año '86, el movimiento se masifica con el anuncio de la municipalización del Instituto Nacional, donde aparecieron acciones más masivas como asambleas y marchas internas e incluso la paralización de las clases.

Sin embargo, la organización estudiantil tenía una participación mucho más activa en la calle, que si bien no era masiva, tenía una orgánica bastante fuerte y buscaba como máxima reivindicación derrocar a la dictadura por la vía de movilización de masas. Según Álvarez, el movimiento estudiantil de los ' 80 combinó lógicas de acción política amplias, con formas radicales y violentas de la lucha callejera entre las que destacaron "la capucha, la molotov, las bombas de ruido, los mercurios (quema de microbuses de locomoción colectiva), las instrucciones militares, etc". (Álvarez, 2005: p.6) No es posible saber cuál fue la magnitud de la presencia de alumnos del Instituto Nacional 
en la lucha callejera, solo es posible reconocer que hubo alumnos con una presencia activa.

La inexistencia de canales democráticos de participación, sumada a la politización estudiantil (que tenía como reivindicación la democratización) generaron organizaciones autónomas de parte del estudiantado, que fueron bastante activas en la lucha contra la dictadura. Sin embargo, por el contexto represivo y autoritario de la época, en lo que se refiere a cuestiones internas del IN, no hubo de parte de estas organizaciones posibilidad de inferir en las decisiones internas del colegio. Por otra parte, tanto el Centro de Alumnos como los consejos de curso continuaron funcionando bajo una lógica bastante poco autónoma e influida por el accionar de los adultos.

La forma en como es concebida la autoridad durante este periodo presenta bastantes continuidades con respecto a la etapa anterior. El profesor en la mayoría de los casos era una figura distante para los alumnos debido a la forma tradicional en que era ejercida su autoridad. De acuerdo a los recuerdos de los ex alumnos, la distancia entre el profesor y el alumno era 'sentida' durante los primeros años, ya que había un contraste entre 'su escuela básica', en la que tenían una mayor nivel de cercanía con sus profesores y el IN. En algunos casos esa experiencia es recordada de manera negativa, ya que "entrar a un colegio tan grande donde dejaste de ser... en ese momento tu dejaste de ser persona, pasaste a ser más un número dentro del grupo; es decir, hablamos que en $7^{\circ}$ éramos en la tarde cerca de 4.000 alumnos, entonces obviamente ya no existía apego, no existía nada... nadie te conocía”. (Alumno CM)

El profesor jefe, en la mayoría de los casos tenía una relación más cercana con sus alumnos, pues debía preocuparse del rendimiento y conducta de cada uno y también de conocer a sus padres. En los relatos de la década del ' 80 aparece la figura del padre asociado al profesor jefe, es decir una autoridad que cuida y sanciona a la vez, como se puede observar en el siguiente extracto: "fue un profesor bastante estricto, era un profesor bastante enérgico, pero bastante cercano a la vez y él tenía el rol... era como un papá dentro del curso, así nos retaba bastante, pero también nos apoyaba mucho." (Alumno CM)

La metodología utilizada en clases era bastante tradicional. En la mayoría de los casos, las clases eran expositivas, sin material de apoyo, donde el aprendizaje dependía exclusivamente del alumno. En este sentido se mantiene 
el aprendizaje de tipo repetitivo que, como se mencionó, al no dejar espacios a las ideas y opiniones del alumno refuerza el estilo autoritario del profesor.

La autoridad era obedecida por el sólo hecho de ser autoridad, es decir, el profesor no tenía que tener ninguna condición personal para ser obedecido, sino que se le obedecía en cuanto tal. Esto se puede observar en el siguiente relato: "obedecías a todos por igual, si no te podías negar a nada, no te negabai a nada, no te podiai negar a nada" (Alumno AZ). El temor durante este periodo continúa siendo una de las razones más fuertes de la obediencia. Los profesores más obedecidos eran los considerados 'más estrictos', es decir aquellos que no te dejaban hablar, reír, que no dejaban ningún espacio al desorden. El miedo tenía su explicación en la posibilidad de ser expulsado del colegio, ya que el que no se adecuaba al comportamiento impuesto por el profesor podía ser expulsado y perder la oportunidad de educarse en el IN.

En algunos casos, el comportamiento iba más allá de mantener una conducta adecuada en la sala de clases y de cierta manera estaba atravesado por el tema político. Esto se puede apreciar en una experiencia relatada por un ex dirigente del PIO:

"AZ: en uno de esos recreos me pilló un profesor fascista, muy facho, el Belfor Aguayo y... un día me vio pegando un papelógrafo y me llevaron donde el rector, y el rector me putió "ite puedo echar en dos minutos, usted que se cree!"

P: ¿y no pasó nada?

AZ: condicional po, no po, ¿Cómo que no pasaba nada? 'Desde este momento usted está condicional y cualquier cosa que pase usted se va de inmediato'. (Alumno AZ)

En el caso relatado, la autoridad del profesor va más allá de exigir una conducta de parte del alumno en la sala de clases, propiciando un perfil de alumno y de persona que se ajuste a los principios del colegio, lo que incluía claramente prohibir su expresión política. Ciertamente el contexto represivo de la época tuvo influencia en las relaciones de autoridad, donde está en ocasiones se teñía de autoritarismo.

Las representaciones que se pueden apreciar en los relatos de los alumnos muestran cierta continuidad con respecto a la etapa anterior. El profesor es respetado en cuanto tal, no existe posibilidad alguna de desacato frente a su autoridad como docente. Esto se refuerza por el uso del silencio, el manejo de 
los tiempos, los rituales al iniciar la clase, y la forma en que el profesor entrega y trasmite el conocimiento. Se trata por tanto de una autoridad tradicional, autoritaria que se desarrolla en una relación con el alumno marcada por la jerarquía.

El retorno a la democracia (1990-1994)

Según los entrevistados de los años '90, la disciplina tenía un funcionamiento similar a lo descrito en las etapas anteriores, pero se pueden ver algunos cambios que se producen de manera paulatina.

Las rutinas diarias de clases, muestran continuidad con respecto a los '70 y '80. Los alumnos debían esperar al profesor ordenados dentro de la sala de clases, cuando este entraba debían pararse para saludar y posteriormente se pasaba la lista. Sin embargo, según un ex alumno egresado el '96, las rutinas variaban de un profesor a otro, "nos poníamos de pie, que se yo, unos profesores más rígidos que otros pero, qué se yo, algunos hasta que no estuviéramos todos de pie, derecho y parados, no te saludaban po. Otros entraban saludando 'siéntense no más chiquillos'" (Alumno AB). En este caso, puede apreciarse ciertos cambios con respecto al periodo anterior. Eso puede deberse a la presencia de profesores con estrategias de ejercicio de autoridad distintas a la tradicional del IN. Para estos profesores ya no era necesaria tanta formalidad al comenzar la clase. Al mismo tiempo, se mantiene el profesor 'a la antigua' que continúa dándole importancia a los ritos, que marcan su presencia y diferencia con los alumnos.

Desde la perspectiva de los ex alumnos, las sanciones tenían bastante peso, inclusive la anotación, ya que "te ponían una anotación y las anotaciones eran importantes en realidad, las consideraban a final de año, podían llamar a tus papás (...) no querías irte para fuera, porque si te pillaba un inspector, tenías que explicarle, en realidad, nadie podía estar fuera de sus sala en horario de clases, entonces te cachaban al tiro, tenías que esconderte, pero ellos siempre andaban dándose vueltas." (Alumno PV)

La presentación personal era uno de los aspectos disciplinarios más importantes del IN, sin embargo, en la década de los ' 90 se presentan matices importantes de mencionar. La presentación personal incluía la chaqueta, camisa adentro, insignia siempre puesta zapatos negros y lustrados y el pelo 
corto. Si el alumno no cumplía con esos requisitos, "siempre habían inspectores en la puerta, en la puerta de entrada, no es que había una revisión así que todos hicieran filas, todo el mundo entraba no más, si pasaba alguien demasiado chascón o con demasiados colores o con demasiadas cosas no lo mandaban de vuelta a la casa, jamás mandaron de vuelta a la casa a alguien por su presentación personal, lo hacían si ir a inspectoría y su anotación." (Alumno AB) El relato muestra que sin haber un relajamiento en el reglamento (se continúa pidiendo la misma presentación personal), hay menos rigidez en el cumplimiento de la norma. En los relatos analizados de los ' 70 y ' 80 el alumno que no cumplía con su presentación personal, sencillamente no podía ingresar al colegio, en cambio a partir de los '90 era llevado a inspectoría, se anotaba en la ficha del alumno y luego podían ingresar a clases.

Durante esta época existía mayor reparo a cumplir con algunas normas de presentación personal. El pelo era uno de los requerimientos que mayor reticencia generaba en los alumnos los que buscaban distintas formas para poder usarlo largo, por ejemplo,

"PR: habían algunos que se peinaban con gel y se doblaban el pelo, se colocaban unos pinches, tenían toda una técnica (risas) era impresionante, habían quienes iban con gorro todo el año, podían haber 30 grados de calor y los gallos andaban con gorro.

P: ¿no le hacían sacarse el gorro?

PR: a algunos sí, pero esto habitualmente andaban escondidos de los inspectores y después claro uno salía a la calle y ellos tenían el pelo súper largo, el tema del pelo era como lo que yo más recuerdo" (Alumno PR)

La década del '90 en el Instituto Nacional, es una época de cambios paulatinos que son un reflejo del contexto que se vive: la transición a la democracia. Los 3 entrevistados pertenecientes a esta década, estudiaron durante años distintos (uno egresó el año 91, otro el 94 y el último el 96), produciéndose en sus relatos pequeños matices que evidencian la existencia de un proceso de transición también dentro del IN.

Esoscambiossonbastanteevidentes en tornoala participación estudiantil, pues el retorno a la democracia significó el desarrollo de una política al interior de los establecimientos donde se buscó darle mayor cabida y autonomía a los estudiantes lo que condujo a elecciones mucho más transparentes y masivas de lo que habían sido en la década anterior. Además la organización estudiantil 
fue estimulada desde los mismos gobiernos, quienes buscaron que los valores democráticos fueran parte importante de las escuelas.

En primer lugar, el año 1991, el decreto 736 sobre Centros de Alumnos es reemplazado por el decreto 524, donde queda de manifiesto el cambio de contexto político del país, indicando la importancia de generar centros de alumnos, ya que "la unidad educativa y sus componentes constituyen el campo propicio para que el estudiante aprenda a vivir en y para la vida democrática" (Mineduc, 1991). En este sentido, los Centros de Alumnos eran concebidos como un espacio de reflexión y práctica para lo que sería su posterior desenvolvimiento cívico.

En cuanto a la organización propiamente tal de los Centros de Alumnos, aparecen dos instancias organizativas nuevas: la asamblea general y la junta electoral. La asamblea general, corresponde a la instancia de participación de todos los alumnos del establecimiento, mientras que la junta electoral, es un organismo creado con la función de "supervigilar y calificar todos los procesos eleccionarios que se lleven a cabo en los organismos del centro" (MINEDUC, 1991). Ambos organismos hacen de los Centros de Alumnos una instancia de participación más democrática.

Otro cambio importante tiene relación con el sistema de elección de la directiva de centro de alumnos, la que "será elegida anualmente en votación universal, unipersonal, secreta e informada" además de establecer como requisitos solo "tener seis meses de permanencia en el establecimiento" y "no haber sido destituido de algún cargo del centro de alumnos por infracción a sus reglamentos" (MINEDUC, 1991). A partir de los '90 se refuerza la elección democrática de las directivas de centros de alumnos, eliminando la elección a través de los delegados de cursos y eliminando ciertos requisitos para participar del centro de alumnos. (Como por ejemplo, la conducta del alumno).

En el relato de los ex alumnos, son evidentes algunos cambios ocurridos en la década del '90. Según el ex alumno egresado el año '91 al recordar sobre la elección de los Centros de Alumnos señala: "puede ser que tuve una vez, una sola vez con un papelito a llenar y hacer algo similar a lo que se hace en el plebiscito." (Alumno PV) Es decir, durante el paso de este alumno por el colegio, eran recientes los cambios en cuanto a la democratización de la participación estudiantil, además de la poca importancia que tenían eventos como este en su vida escolar. En cambio, al preguntar a un ex alumno egresado el '96, este recuerda que las elecciones se realizaban "por votación, por lista. 
[Y se hacía] toda la faramalla, toda la... letreros grandes colgando del patio. Una campaña además muy política, yo después entendí en $3^{\circ}$ y $4^{\circ}$ medio que efectivamente era muy política la campaña. Que las listas tenían su asociación política, habitualmente había una cosa casi partidista de parte de las listas." (Alumno AB).

La 'repolitización' que se aprecia en los relatos, se distingue de la de los ochenta por su carácter institucionalizado. Los partidos políticos tienen cabida en el Instituto y pugnan por la influencia dentro de este. Por el mismo carácter institucionalizado de la política, esta se vuelve más masiva. El ejemplo más notorio de esto fueron las elecciones del Centro de Alunmos del Instituto Nacional donde destacaban la trascendencia de las campañas, la publicidad de estas, los debates, con un alto contenido político. Esto claramente se opone a la politización clandestina que se vivió durante los ochenta.

El consejo de curso, continúa siendo durante estos años la instancia de participación más activa de los institutanos con funciones bastante similares a los años anteriores: organizar fiestas, paseos de fin de año, preparar la semana del colegio, etc. Sin embargo llama la atención la importancia que se le daba a esta instancia y la autonomía que van adquiriendo con el tiempo los alumnos con respecto a los profesores. Según un ex alumno egresado el '94, el consejo de curso "lo hacía el [presidente] pero siempre iba conduciendo un poquito la profesora, la profesora tocaba los temas, planteaba temas que paulatinamente se tenían que ir tratando, pero en general estaba abierta la posibilidad qué nosotros teníamos alguna duda y el presidente de curso la planteaba, (...) se tomaba bastante, bastante en serio la hora que teníamos semanalmente de consejo de curso" (Alumno PR). Mientras que el ex alumno egresado el '96 sostiene que "el profesor no metía la cuchara casi nunca... en el fondo siempre estuvo la idea de que la directiva se hiciera cargo de la organización, de la planificación y de la ejecución del consejo de curso" (Alumno AB). Se puede apreciar en estos relatos que las directivas de cursos fueron adquiriendo mayor autonomía y teniendo durante esa hora de clases, control absoluto sobre lo que se hacía. Esto es demostrativo del aumento de las instancias de participación propiamente estudiantiles, y la autonomía que van adquiriendo los alumnos con respecto a la autoridad del profesor.

A simple vista las concepciones sobre la autoridad que poseen los ex alumnos sobre los profesores no cambiaron mucho con respecto a las etapas anteriores. En primer lugar hay una visión bastante similar cuando se les pregunta sobre cómo eran los profesores del IN, ya que estos rescatan su 
calidad profesional, su conocimiento, además de la exigencia que tenían con los alumnos. Por otra parte, los entrevistados sostienen que en su mayoría los profesores eran bastante respetados y que los alumnos cooperaban con ese clima de respeto.

A pesar de apreciarse una cierta continuidad, es evidente que existe un mayor grado de cercanía entre el profesor y el alumno que se da en algunos casos. El apelativo 'señor' para dirigirse al profesor, comienza a desaparecer (sólo el ex alumno egresado el 91 señala que se llamaba al profesor de esa manera) y es reemplazado por profe o profesor. Al alumno en cambio se le continúa llamando por el apellido, y muy rara vez, cuando estos eran más cercanos, por el nombre. Esto da cuenta de una relación bastante impersonal, pero menos formal y marcadamente jerárquica que en las etapas anteriores.

Pese a que los ex institutanos señalan que con la mayoría de los profesores hay una relación distante (sobre todo al comienzo cuando ingresan a séptimo básico), aparece la figura del profesor "amigo", aunque este siempre cumplía con un rol severo en lo estrictamente académico. Tal como lo expresa un ex alumno: "un gallo que, bueno, a medida que uno avanzaba en edad, se hacían más cercanos a ti en lo personal, el gallo que se preocupaba de ti, se preocupaba de tu familia, conocía a tu familia, que era así... que le gustaba echar la talla contigo, que ya hablaba a garabato limpio contigo a veces... un compadre más. En lo académico siempre severo y esa era la gracia, en el fondo que "puta compadre, te tengo que poner un rojo", "yo te quiero mucho pero esto te lo mereci" "sí, no se preocupe profe" ¿cachay? Ese tipo de relación súper directa, súper frontal pero en lo académico si correspondía, correspondía no más" (Alumno AB). Surge la figura del profesor que tiene una preocupación mayor por el alumno como sujeto, más allá de sus notas, que se preocupa por su condición emocional, por conocerlo, pero sin dejar de ser una figura de autoridad en el momento de hacer clases, enseñar y evaluar. Este tipo de profesor no aparece de manera tan evidente en las épocas anteriores, por lo que suponemos que si existió deben haber sido casos muy excepcionales.

En términos pedagógicos, permanece la idea de que es el alumno el que debe aprender de manera autónoma, con menor compañía del profesor de lo que ocurría en la escuela básica. Sin embargo, junto a la clase expositiva aparecen instancias de mayor participación de los alumnos en su propio aprendizaje como: debate durante la hora de clases, discusión sobre temas de actualidad, grupos de trabajo, investigación y exposiciones. Con la inserción de nuevas estrategias de enseñanza, se pone de manifiesto que existe una forma 
de concebir la pedagogía centrada en el aprendizaje del alumno, más que en lo que enseña el profesor. Es por tanto un aprendizaje más activo y centrado en lo que tiene que "hacer" por sí mismo el alumno. Este tipo de pedagogía genera relaciones de mayor cercanía y dialogo, puesto que es a partir del 'mundo del alumno' que el profesor puede enseñar los contenidos. Este cambio es evidente en las entrevistas de los noventa.

Otro de los cambios significativos que existen en la relación entre profesor y alumno durante esta época tiene que ver con las razones de la obediencia. Al preguntar a los ex alumnos porque obedecían al profesor, reaparece la figura del profesor estricto al que se le obedece por miedo. Sin embargo, esos profesores sumamente estrictos a los cuáles se les temía comienzan a ser una excepción, ya que generalmente son los profesores más antiguos del colegio, que van siendo reemplazados por otro tipo de profesores. De acuerdo a los ex alumnos el otro tipo de profesor que más se obedecía era al profesor considerado "capo" en su asignatura, el que te enseñaba.

Al mismo tiempo aquel que era considerado un mal profesor académicamente 'fracasaba'. Por ejemplo "Yo me acuerdo de haber llegado una profesora así súper amorosa y ella media hipienta, que se yo, y que más encima no era tan seca como otros profesores que habíamos tenido y no la pescábamos no más po" (Alumno AB). Como se puede ver en este relato, el alumno del IN 'juzga' al profesor en cuanto a su conocimiento y capacidad de enseñar. Es decir, ya no existe una obediencia ciega a cualquier figura de autoridad, puesto que aquel que no tiene el conocimiento suficiente no es reconocido por los alumnos. A través del relato se puede ver que la manera en la que se desacata a esta autoridad es 'no pescar', no implica una posición del alumno de enfrentamiento al profesor o una postura de conflicto frente a este. Cosa que si puede apreciarse en el periodo posterior. El desacato al profesor como figura que enseña, es algo que evidencia un cambio bastante notorio con las épocas anteriores.

\section{Los años de crisis (2006-2010)}

Como se puede apreciar a través de los distintos periodos, las normas de disciplina escolar siempre fueron las mismas, e incluso se repiten en este último periodo. Al interior de la sala de clases, el profesor pedía un comportamiento adecuado que incluía, el saludo que debe ser de pie, seguido de la lista, y 
además que los alumnos pidieran permiso para realizar ciertas acciones como opinar en clases, pararse, salir de la sala, etc. Al igual que en los periodos anteriores, si el alumno transgredía una norma que podían ir desde conversar a situaciones de gravedad como fumar, pelear, etc. se le aplica una sanción que luego es registrada en su ficha de vida o ficha conductual. En síntesis el sistema disciplinario era básicamente el mismo.

Lo interesante aquí, es que pese a que la forma en la que se establece la disciplina es igual, a través de los relatos se pueden apreciar concepciones sobre este sistema diferentes, y que dan cuenta que las mutaciones de la autoridad ocurren también en el plano de la dimensión formal de la autoridad.

En primer lugar cabe señalar que hay una visión generalizada de que el alumno del IN respeta las normas. Esto como se ha dicho está estrictamente relacionado con esa suerte de pacto que existe para que no ocurra la expulsión del colegio. Sin embargo, la importancia que tienen para estos las sanciones no son las mismas de los periodos anteriores. Por ejemplo al preguntar sobre la importancia de las anotaciones señalan: "no pesaba mucho, pero por ejemplo en la hora de orientación la profesora pescaba así la hoja y se ponía a revisar si es que un profesor había escrito algo, y ahí te daban como el sermón, pero no importaba mucho" (Alumno JA) En este ejemplo, evidentemente la profesora le da gran relevancia a las faltas que cometen los alumnos, y los alumnos no le dan mayor importancia. La anotación a partir de este periodo ha perdido la 'sensación de miedo' a la que estaba asociada en periodos anteriores.

En la sala de clases, al momento del saludo existían diferentes tipos de profesores: "había profesores o 'profesor que en paz descanse' que decía yo no voy a empezar la clase y nos tenía a todos parados. Ya párense, y hasta que se queden en completo silencio, nadie se va a sentar y se sentaba él y se ponía a leer el diario. 'Todavía no se callan' una vez estuvimos parados como 45 minutos y hasta que ya después nos sentábamos. Habían profesores que les daba lo mismo y llegaban estaban todos leseando y seguían leseando" (Alumno ES).

En el Instituto Nacional conviven profesores de distintas generaciones, que tienen maneras de concebir su autoridad de forma diferente, y esto es percibido por los alumnos. El profesor 'a la antigua', por así decirlo le da una gran importancia al rito de inicio de clase de modo de inculcar en sus alumnos rutinas. Pero al mismo tiempo está el profesor al que no le importa darle mayor realce a estos ritos diferenciadores. En el último periodo conviven distintos tipos de ejercer la autoridad. Si bien las reglas conductuales son las mismas, hay 
una especie de relajamiento de estas que no solamente va de parte del alumno, sino que también del profesor. Hay profesores que no le importan ciertas rutinas que eran esenciales para los profesores de años anteriores.

El cambio más evidente que ocurre en esta época se da a nivel de la participación estudiantil, donde los alumnos llegan a niveles de autonomía y presencia pública insospechada en épocas anteriores.

En términos institucionales, el año 2006 se realizan pequeñas modificaciones al reglamento de Centros de Alumnos del año ‘90, que tienden a reforzar el carácter democrático y la autonomía del estudiantado. Se agrega que "en ningún establecimiento se podrá negar la constitución y funcionamiento de los centros de alumnos" (Mineduc, 2006), es decir se le da un refuerzo desde el estado a la existencia de los Centros de Alumnos. Y por último, establece que los dos asesores del centro de alumnos, que antes eran designados por la dirección, pasan a ser designados por la directiva del centro de alumnos. Estas medidas claramente refuerzan el carácter independiente de la organización de los alumnos, reforzando su posición dentro del establecimiento. En el Instituto Nacional, el cambio más significativo con respecto a la etapa anterior, es la eliminación del requisito de notas para ocupar cargos en la directiva del Centro de Alumnos.

El refuerzo de la posición que ocupan las organizaciones estudiantiles dentro de los colegios se intensifica con los acontecimientos que ocurren durante este periodo. La 'revolución pingüina' les dio a los estudiantes un empoderamiento nunca visto en las últimas décadas. Los ex institutanos señalan que la directiva del centro de alumnos, toma un rol político y social liderando las movilizaciones estudiantiles. En ese sentido "el centro de alumno es la instancia es que para mí que mediaba los conflictos externos más que nada y los internos, digamo uno de los que vi, a lo largo de mi estancia, tuvimos nuestros problemas internos y externos, cosas de los cambios de rectores y el conflicto estudiantil 2006 y al final un rato el 2008. Para mí el centro de estudiantes era ver si esas personas que al final daban la voz de decir marchamos, sí mandamos la carta para que echen a este tipo, más que nada eso, porque yo creo que esa era su labor" (Alumno ES)

Con la radicalización del movimiento estudiantil, específicamente en las tomas, aparece una organización diferente a lo establecido institucionalmente, donde surgen líderes independientes de la directiva del Centro de Alumnos. Si bien estos últimos continúan siendo la cara visible de la organización -sobre 
todo hacia fuera- surgen liderazgos propios de las organizaciones. Ya en la toma, "se armaba como el jefe de cada eh... de cada división, de cada comisión y ese ya era como reconocido, entonces era como había uno de seguridad, había uno de tanto, de... y eso era como el que... el más reconocido. (...) Aparte del centro de estudiantes que de repente estaba metido dentro de estas comisiones, se legitimaba por ser del centro de estudiante, estaban los otros que por un tema de participación no más, de estar metido en el tema." (Alumno LS)

A nivel de consejo de curso, si bien este mantiene su rol principal como: organizar paseos, fiestas, semana del colegio y resolver temas puntuales del curso (notas, correr alguna prueba, fotocopias), también es permeado por los movimientos estudiantiles. Durante el consejo de curso, "se discutían las cosas más o menos, que estaba pasando, porque se estaba alegando, que pasaba con la no sé, con la jornada escolar completa en ese tiempo y todas las demandas que surgieron, entonces uno se informaba un poco por lo menos, siempre habían algunos que no querían participar pero la mayoría si estaba adentro y participaba u opinaba y se llegaba a un concenso como curso." (Alumno LS)

Las movilizaciones también le dieron más autonomía a los cursos en relación al profesor jefe, ya que las decisiones y temas a discutir eran estrictamente de los alumnos. Tal como recuerda un ex alumno: "en cuarto a la profe igual le gustaba como meter la cuchara en los temas de nosotros, pero no era como que ella tuviera incidencia, como vamos a hablar de esto, no. Ella nos dejaba a nosotros discutir nuestros puntos, nuestra tabla" (Alumno JA).

Al preguntar a los ex alumnos sobre sus profesores, reaparece la idea de que en el Instituto Nacional, 'el profesor es respetado'. Sin embargo, durante este periodo aparece de manera mucho más evidente 'la crítica'. Los ex alumnos de este periodo tienen una postura mucho más crítica sobre el colegio, lo que se puede explicar por varias razones. En primer lugar, por la cercanía temporal con los años en que estudiaron, por lo que aquellas experiencias posiblemente negativas que vivieron en el colegio están más presentes en sus recuerdos. También porque durante su paso por el colegio se vivió un momento clave en el debate sobre la crisis de la educación pública, donde también sirvió de debate para los problemas interno del Instituto Nacional. También el espíritu crítico que se expresa en este último grupo de estudiantes, refleja los cambios sociales que se han producido en Chile en los últimos años. En la sociedad chilena hay una expectativa cada vez mayor de horizontalidad en las relaciones sociales. Dentro de esta dinámica, existe desde las generaciones más jóvenes un 'reconocerse igual' a la generación adulta, lo que implica mayor cercanía, 
pero a la vez una postura más incrédula con respecto esta. No existe un respeto al adulto por el sólo hecho de serlo, la relación requiere de un proceso de construcción, de confianza.

Las críticas apuntan en varios sentidos, en primer lugar los ex alumnos reconocen que como en todos los colegios también hay malos profesores en el Instituto Nacional, otros señalan que la mayoría "son unas máquinas de hacer clases", y que no se preocupan del ámbito espiritual de los alumnos y otros señalan que existen profesores que "no hacen su pega".

Los ex alumnos aprecian sobre todo el conocimiento y dominio del tema que poseían los profesores. Esto desde su perspectiva explica también las razones de su obediencia. En ese contexto, se respetaba al profesor por su amplio dominio del contenido, independiente de como fuera este. Un ejemplo muy claro del respeto que se le tiene al profesor por su conocimiento es el caso de Belfor Aguayo, quien es recordado por un ex alumno de la siguiente manera: "el profesor de matemáticas era el caso más conocido, él sabía mucho, sabía mucho de matemáticas, sabía de todo, de botánica, de geografía, todas las cuestiones y él era como malo así, echaba a los alumnos por negros, tú erí muy moreno te vay, no quiero verte" (Alumno ES). Pese a las 'malas prácticas' que de la perspectiva de este ex alumno poseía este profesor, éste fue uno de los más recordados en los relatos de los alumnos y todos concuerdan en que era muy respetado por el conocimiento que poseía. Este caso es demostrativo de la importancia que le otorgaban los institutanos al conocimiento del profesor por sobre otras cualidades.

En ese mismo sentido, los profesores más obedecidos, eran los profesores de las asignaturas consideradas 'importantes', es decir "los de matemática y lenguaje, matemáticas sobre todo, era como muy jerarquizado matemáticas, lenguaje, ciencias sociales, ciencias naturales y después venía tecnología y arte, cachay, los puntajes nacionales al colegio, los que le van a dar plata al colegio, los que le van a dar renombre al colegio." (Alumno JA) Muchos de los estudiantes que estuvieron en esta última etapa poseen una visión pragmática de su paso por el colegio, y esto también incide en el tipo de relaciones que se da entre el alumno y el profesor, puesto que aquellos profesores que eran más obedecidos estaban directamente relacionados con el futuro de los alumnos, el que me va 
a permitir dar una buena PSU e ingresar a la universidad y finalmente tener un futuro 'asegurado'.

Lo mismo ocurre a la manera inversa, los profesores menos obedecidos eran aquellos que a juicio de los alumnos, no estaban bien preparados académicamente. Es bastante demostrativo un episodio relatado por uno de los ex alumnos: "Había profesores nuevos que eran comidos por los alumnos, se sabía, sobre todo en Inglés que había una profesora que llegó y duró dos semanas, cachay porque los alumnos se la comieron, o sea, creo que había uno que fue lo que le hizo, empezó a hablar en Inglés, pero muy fluidamente y ella le dijo, pero haber, tranquilo sí estamos aprendiendo todos, y él le siguió hablando, le siguió hablando, le siguió hablando y como que ella sintió tanta presión que se tuvo que ir" (Alumno JA). En este caso, los alumnos no sólo no obedecen al profesor, sino que lo desafían, realizando una clara crítica a su desempeño profesional. Se produce un desacato a la autoridad, que no solo atenta contra la persona, sino que a la condición misma del ser profesor. En esta última etapa es posible sostener que la autoridad del profesor es más 'vulnerable', pues está siendo constantemente desafiada por los alumnos.

\section{Conclusiones}

Al adentrarse en la cultura del Instituto Nacional a través de sus libros de clases, documentos, pasillos y patios, pero sobre todo a través de las experiencias de alumnos lo primero que se destaca es su excepcionalidad. La importancia que tiene el pasado para su cultura escolar (su gloriosa fundación y los hombres importantes que han pasado por sus aulas) ha permitido que generación por generación se transmita la idea de que el Instituto es excepcional. Esta supuesta excepcionalidad influye en que los alumnos y profesores también se perciban como 'únicos' y como tales valoren su experiencia escolar.

El Instituto Nacional tiene una cultura escolar marcada en primer lugar por el exitismo académico (la mayoría de los alumnos del Instituto obtiene buenos resultados en la PAA o PSU e ingresa a la universidad, ese por lo menos es el objetivo de todo institutano). Esto es lo que aún hoy -con todos los problemas reconocidos a nivel nacional por las últimas movilizacionespermite que mantenga alta su matrícula. En esa perspectiva, el Instituto se 
ha instalado como lugar de movilidad social precisamente por los buenos resultados que se obtienen en las pruebas estandarizadas.

En segundo lugar la cultura escolar del IN está marcada por la tradición y por el uso que se hace mediante diferentes estrategias de esa tradición. Como se apreció tanto en los discursos, rituales, documentos y salas de clases se transmite de generación en generación que 'no cualquiera pasa por ahí', lo que como se señaló hace sentir a los alumnos como únicos. Esta condición privilegiada que antiguamente se explicaba por la condición de élite de quienes entraban al Instituto Nacional, hoy es comprendida como esfuerzo individual, en el discurso actual es la meritocracia la que explica la movilidad social.

En términos de las representaciones de la autoridad el instituto es sin lugar a dudas, un caso particular en el sentido de cuanto se exacerba la noción y las prácticas de la autoridad de profesores, quiénes tienen el poder de decidir quién puede permanecer como estudiante y quién no, en un colegio "excepcional" que asegura la movilidad social por vía de la meritocracia. En ese sentido, el estar afuera o dentro del Instituto implica una suerte de "pacto", que organiza la disciplina escolar y el rendimiento escolar.

A través del análisis de las entrevistas a los alumnos es posible concluir que existe un camino paulatino desde una figura de autoridad tradicional (típica del profesor rígido, fuerte y total), a una figura de autoridad democrática (profesor que dialoga, escucha, da segundas oportunidades). Sin embargo, el camino de un tipo de autoridad a otra no implica que la desaparición de la otra.

Durante la década de los '70 y los '80, es mucho más visible la figura de autoridad tradicional, que se observa en un profesor que marca las pautas de la clase, la importancia del silencio, el monopolio de la palabra y del conocimiento, en la preocupación por el buen comportamiento del alumno e incluso la presentación personal de este. Es decir, en las rutinas cotidianas de la escuela, las jerarquías estaban bastante marcadas. En ese contexto la razón principal para la obediencia era el 'miedo', donde el simple 'reto' del profesor era bastante efectivo. El miedo era además exacerbado por la imposibilidad de expresarse de los alumnos, debido a las casi inexistentes instancias de participación, y además muchas veces de que la figura de autoridad estaba teñida de autoritarismo. En este contexto, si bien en los ' 80 existió una rebeldía 
juvenil esta fue clandestina, silenciada y por lo tanto no hubo un desafío a la autoridad en la cotidianeidad de la sala de clases.

A partir de los '90, comienza a aparecer, una nueva figura de autoridad marcada por el diálogo, el consenso, una mayor preocupación y cercanía con el alumno, además de la democratización de las organizaciones estudiantiles.

En el ámbito pedagógico las nuevas concepciones sobre el proceso de enseñanza-aprendizaje (constructivismo), permiten al alumno un rol más activo en su propio aprendizaje, produciendo un mayor reconocimiento del alumno como sujeto y como ente capaz de aprender por sus propias capacidades. El aprendizaje de alguna manera deja de ser monopolio del profesor.

En este escenario, el alumno obedece por el deseo de aprender y particularmente el interés que le provoca ese profesor considerado 'bueno'. Durante esta etapa se debilita la obediencia por el rol de la autoridad pedagógica y por tanto pasa a ser una autoridad más vulnerable, menos intocable, lo que se traduce en un mayor relajamiento de ciertas rutinas propias de la clase y en el aumento del 'desacato a la autoridad'. Si bien el desacato se presenta a lo largo de los periodos estudiados es a partir de esta etapa que hay mayor juicio al profesor en cuanto a su rol pedagógico, es decir, como figura poseedora de conocimiento, monopolio para evaluar académicamente, modelador de conductas, etc.

Por otra parte, el movimiento estudiantil incidió en el ejercicio de la autoridad, puesto que este significó (sobre todo durante las tomas) el control de los espacios. El 'ocupar el colegio' significó ocupar un rol que antes era monopolio del profesor, de ahí que estos sientan debilitada su autoridad después de esos acontecimientos.

Es evidente que la autoridad en la escuela ha mutado en los últimos 40 años, pero ¿Qué ha incidido en el cambio entre una autoridad 'tradicional' a una 'democrática'?

Durante las últimas décadas se han producido cambios sociales que han apuntado a una mayor horizontalidad en las relaciones sociales. Esto ha conducido a una relación entre adultos y jóvenes, caracterizada por el dialogo, el consenso, la comprensión etc. Esto ha favorecido la democratización de las 
relaciones sociales en la escuela y por tanto, ha influido en las formas en que se ejerce la autoridad.

Junto con esto, los cambios que se han producido en el sistema escolar y en el país, han tendido a reforzar la existencia de una autoridad democrática en la escuela. En ese sentido, la escuela chilena, al no ser un espacio aislado de lo social, ha sufrido importantes transformaciones que van de la mano con los cambios socio políticos de la historia reciente chilena. De alguna manera el largo camino desde la dictadura hacia la democracia, y particularmente las luchas por acabar con el régimen autoritario y posteriormente por avanzar hacia una verdadera democracia, han tendido a democratizar las relaciones sociales en la escuela.

A partir del '90 con la apertura y participación estudiantil hay un nuevo tipo de profesor, lo que se combina con una suerte de empoderamiento de los estudiantes como actores sociales, lo que queda demostrado en los movimientos estudiantiles: "los adultos no fueron capaces de cambiar el sistema educativo, sino que serán los jóvenes". Es decir, a nivel político y social hay una definición de roles, una construcción de nuevos imaginarios sobre las representaciones de lo que es ser joven y lo que es ser adulto.

Ahora bien, esto no implica necesariamente la crisis, o el fin de la autoridad, sino que ésta ha ido mutando, adaptándose al nuevo contexto. En el espacio escolar existe una presión por parte de la sociedad para que la autoridad del profesor se funde sobre principios y valores cada vez más democráticos. 


\section{Referencias bibliográficas}

Alvarez Rolando (2005). "El Movimiento estudiantil secundario bajo la dictadura y las juventudes comunistas: un caso de radicalización política de masas en Chile (1983-1988)". Alternativa, 23, Santiago.

Bernstein Basil, (1988). Clases, códigos y control, Ediciones Akal,

Boero Lillo Ernesto, (1963). Crónicas de siglo y medio del Instituto Nacional de Chile, Santiago, Ediciones Boletín del Instituto Nacional, Santiago.

Cox Cristián (2005). "Las políticas educacionales de Chile en las últimas dos décadas del siglo XX, Politicas educacionales en el cambio de siglo. La reforma del sistema escolar de Chile, Editorial Universitaria, Santiago.

Egaña María Loreto (2000). La educación primaria popular en el siglo XIX en Chile: Una práctica de politica estatal, DIBAM, Santiago.

Gallo Paola (2011). Respeto y autoridad en el espacio escolar. Mutaciones y supervivencias de sus valores constitutivos, libros de la araucaria, Buenos Aires.

Instituto Nacional (1984). Circular del Instituto Nacional, Santiago.

Instituto Nacional (1989). Libreta de comunicaciones Instituto Nacional, Santiago.

Instituto Nacional (2011). Proyecto educativo Institucional, Santiago.

Lechner Norbert (1982). La vida cotidiana en Chile: La experiencia escolar, FLACSO, Santiago.

MINEDUC (1974). Circular n³.

MINEDUC (1985). Decreto 726.

MINEDUC (1991). Decreto 524.

MINEDUC (2006). Decreto 50.

Miranda Marcelo (2003). "El mito de los elegidos", El periodista, [En línea], 
lunes 31 de marzo de 2003, [consultado el 18 de octubre de 2012]. Disponible en: http://www.elperiodista.cl/newtenberg/1355/article-30819.html

Núñez Iván (1986). Gremios del magisterio: setenta años de historia 1900-1970, PIIE, Santiago.

PIIE (1985). Las transformaciones educacionales bajo el régimen militar, Santiago.

Sala de Historia, Ranking histórico PSU [En línea] [Consultado el 15 de enero de 2013]. Disponible en: http://saladehistoria.com/wp/2011/08/31/rankinghistorico-psu/

Seremi de Planificación y coordinación (2002). Región metropolitana de Santiago cambios demográficos 1990-2020: análisis proyecciones de Población INE, Santiago.

Toro Pablo (2008). "Disciplina y castigos: fragmentos de la cultura escolar en los liceos de hombres en Chile en la segunda mitad del siglo XIX", Cuadernos Interculturales, $\mathrm{n}^{\circ} 11$, Santiago.

Weber Max (2007). Sociología del poder. Los tipos de dominación, Alianza Editorial, Madrid.

\section{Entrevistas}

- Entrevista alumno AE (1970-1975), realizada el 17 de Octubre de 2012.

- Entrevista alumno HA (1975-1979) realizada el 13 de Noviembre de 2012.

- Entrevista alumno CG (1970-1974), realizada el 23 de Octubre de 2012.

- Entrevista alumno PA (1982-1987), realizada el 30 de Noviembre de 2012.

- Entrevista alumno AZ (1983-1988), realizada el 14 de Diciembre de 2012.

- Entrevista alumno CM (1982-1987), realizada el 17 de Octubre del 2012.

- Entrevista alumno PV (1986-1991), realizada el 13 de Diciembre de 2012.

- Entrevista alumno AB (1992-1997), realizada el 19 de Diciembre de 2012

- Entrevista alumno PR (1988-1994), realizada el 13 de Diciembre de 2012.

- Entrevista alumno JA (2003-2008), realizada el 26 de Diciembre de 2012

- Entrevista alumno ES (2003-2008), realizada el 17 de Enero de 2013.

- Entrevista alumno LS (2003-2008), realizada el 28 de Diciembre de 2012. 